\title{
Myxoma of the maxillary sinus
}

\author{
Rajeev Puri Professor, Sandeep Bery, Senior resident, \\ Lok Nayak Hospital New Delhi - 110002 India \\ A. K. Mandal, Professor, Department of pathology \\ Maulana Azad Medical College \\ New Delhi - 110002 India
}

\section{Abstract}

A case of Myxoma involving the maxillary sinus in an 11 year old girl is being reported for its rare occurance in children.

\section{Key Words}

Myxoma ; Maxillary sinus ; Stellate Cells

\begin{abstract}
$0_{\text {sseous myxoma is a benign, slow growing locally invasive tumour of the facial }}$ skeleton. It frequently manifests as a slow growing palatal or facial swelling. It usually occurs in adolescents, unommon in adults and is rare in children. ${ }^{1}$

We are reporting a case of myxoma in a young girl of 11 years, keeping in view the rarity of this tumour in children.

\section{Case Report}

An 11 year old girl was seen in the ENT outpatient department with the complaint of swelling over the right side of the face for last four months. Patient gave a history of an increase in the size of the swelling for last three months. There was no associated history of trauma, pain, fever or tooth extraction. Physical examination revealed swelling approximately $6 \times 7 \mathrm{~cm}$, irregular, overlying the
\end{abstract}


right maxilla. There was fullness of the right gingivolabial sulcus with the overlying mucosa being intact. Anterior rhinosopy revealed the lateral wal of the right nasal cavity pushed medially and no other mass seen. The skin overlying the swe!ling was normal. X-ray of the paranasal sinus showed homogenous opacity of the right maxilla and right nasal cavity. (Fig 1) The fine needle aspiration

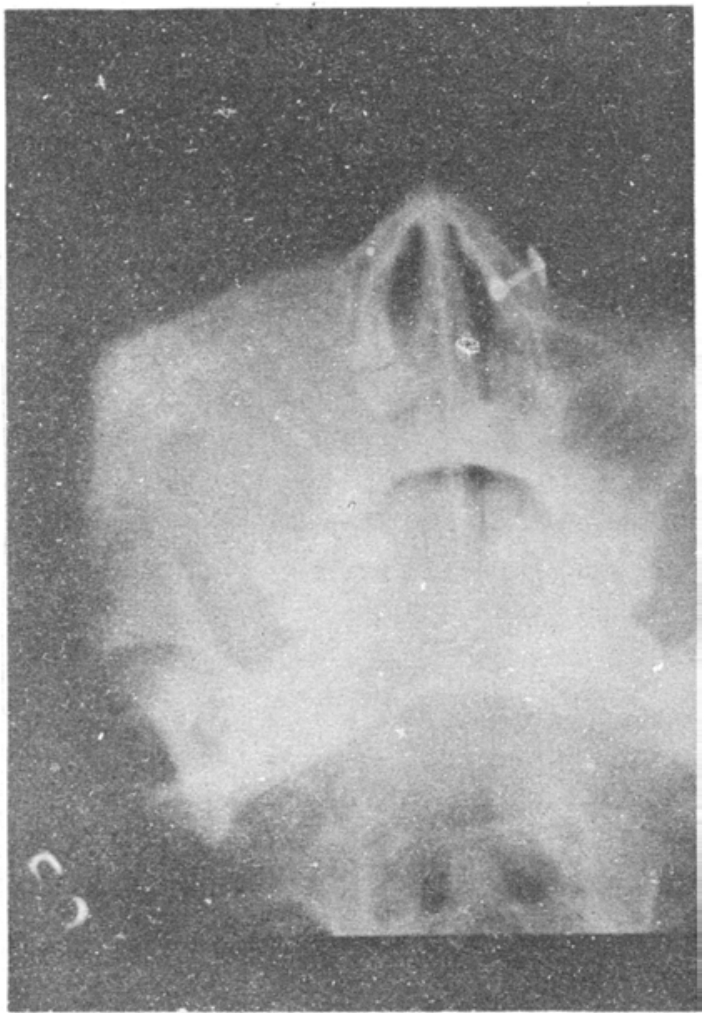

Fig I. X-ray of the paranasal sinus showing homogenous opacity of the right maxillary sinus and right nasal cavity.

cytology done of the swelling through the bulge in the right gingivolabial sulcus proved inconclusive. CT scan of the paranasal sinus, however could not be done as patient could not afford it. The general physical examination was normal., After getting the routine investigations, patient was prepared for surgery under general anaesthesia. A provisional diagnosis of a benign pathology was kept. Patient was taken for excision via a sublabial approach. The bony plate was very thin. Myxomatous tissue was found completely filling the right maxillary antrum and also causing its expansion. The mass was enucleated completely. An antrostomy was fashioned and the removal of the medicated pack was done 48 hours post- operatively. The patient was followed up regularly at weekly intervals and is symptom free. The histopathological examination of the mass removed showed myxoma.

\section{Histopathology}

Grossly multiple polypoidal gray white and gelatinous tissue was identified Microscopically, the polpys consist of loose gelatinous tissue with numerous stellate cells. There is mild to moderate chronic inflammation. At places the overlying epithelium is ulcerated. In rest of the places, the tissues are lined by flattened cuboidal epithlium. ( Fig II )

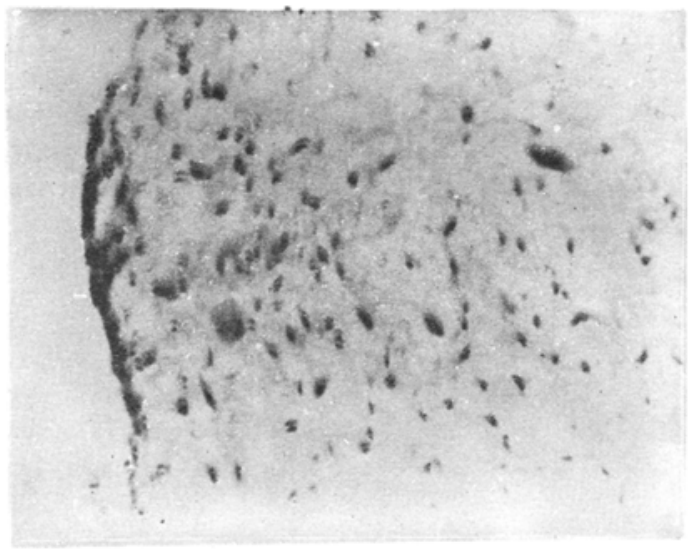

Fig II. Microphotograph showing stellate shaped cells in a myxoid stroma.

\section{Discussion}

Virchow in 1871 was first to describe myxomas. ${ }^{2}$ Histologic criteria for diagnosis of myxoma was redefined by Stout. ${ }^{3}$ Differentiation of the myxomas arising from maxilla and mandible, was first described by Thoma and Goldman. ${ }^{4}$ They were found to constitute $0.1 \%$ of all primary bone tumours, the average age of occurrence was 30 years and no sex predilection was observed. It was also reported by them, that these tumours are uncommon in adults and rare in children. In the present case report, we have described a myxoma of the maxilla in an 11 year old girl emphasising the rarity of this tumour in 
children. Various studies done in the past have confirmed the rarity of this pathology in children. Dutz and $S_{\text {tout }}{ }^{2}$ reported 15 myxomas in children whereas smith et al $^{5}$ described 27 such cases in children. In a comprehensive review done in $1977^{6}$, only 20 cases of myxomas were found in patients younger than 18 years.

Osseous myxomas tend to grow within the anatomic boundaries with the displacement of adjacent bony structures. Their predilection is for the bones of the jaws. ${ }^{7}$ Fine needle aspiration cytology was inconclusive in establishment of preoperative diagnosis in the present case. David K Haynes et $a^{6}{ }^{6}$ stated that cytological examination by fine needle aspiration can be difficult to interpret, because obtaining an adequated sample from a child in whom the tumour has a bony shell is difficult. Radiological studies especially CT scan and MRI, are useful in determining the extent of the tumor before surgery. ${ }^{6}$ However, due to unforeseen circumstances, CT scan / MRI could not be done in the present study.

Corrective management of myxoma of maxilla involves a radical primary resection inspite of signficant functional and aesthetic sequelae. Enucleation or curettage is inadequate treatment as chances of recurrence with aggressive behaviour are high. ${ }^{6}$ However, in children, to avoid future asymmetries and dental abnormalites, one should try to maintain facial growth centres. ${ }^{5}$ Keeping the above fact in mind, as also the age of the child, complete enucleation of the mass via a sublabial approach was done in this case. Follow up of a patient of myxoma, who has under gone surgery, should be meticulous with regular clinical and radiographic examinations. ${ }^{1}$

\section{References}

1. Deron, P. B., Nikolovski, N., Hollander, J. C. D., Spoelstra, H. A. and Knegt, P. P. (1996) : Myxoma of the maxilla: A case with extremely aggressive biologic behaviour. Head and Neck $18: 459.464$.

2. Dutz, W. and Stout, A. P. (1961) : The myxoma in childhood. Cancer $14: 629-635$.

3. Stout, A. P. (1948) : Myxomas, the tumour of primitive mesenchyme, American Journal of Surgery $127: 706-718$

4. Thoma, K. H. and Goldman, H. M. (1942) : Central myxoma of the jaw. American Journal of Orthodontics and Oral Surgery $28: 540-542$.

5. Smith G. A., Konrad, H. R. and canails, R. F. (1977) : Childhood myxomas of the head and neck. Journal of Otolaryngology $6: 423-430$.

6. Haynes, D. K., Madsen, J. M., Simpson, R. and Jarchow, R. C. (199I) : Myxomas of the maxilla in infants and children. Otolaryngology-Head and Neck Surgery 105 (3) : $464-48$.

7. Batsakis, J. G. (1987): Myxomas of the soft tissues and facial skeleton. Annals of Otolology, Rhinology and laryngolology 96: 618-619. 